\title{
Students' Self-assessment: A Learning Tool and Its Comparison with the Faculty Assessments
}

\author{
${ }^{1}$ Syed Rashid Habib, ${ }^{2}$ Haneef Sherfudhin
}

\begin{abstract}
Objective: This study compared the student's self-grades versus the examiners grades, inter examiner grades and grades of anterior with posterior teeth in a preclinical prosthodontic course.
\end{abstract}

Methods: 75 students and 2 examiners participated in the study. The students prepared one anterior (upper central incisor) and one posterior (lower first molar) teeth for full veneer crowns in allocated time of 2 hours and 30 minutes. After the preparations, the students self-graded their preparations based on criteria-based evaluation forms. The examiners also completed the grading for the prepared teeth. All the grades were recorded, comparisons were made using SPSS version 21 and results tabulated.

Results: The means of grades (8.32) by the students themselves were found to be higher compared to the examiners grades (7.3) for the anterior as well as posterior teeth. Comparison of the grades for the anterior/posterior teeth and the overall grades showed a statistically significant difference $(p=0.000)$. A moderate correlation (0.399) and a strong correlation (0.601) were found between the grades of the faculty and the students for the anterior and posterior teeth respectively. The overall grading for the anterior and posterior teeth by the two faculty members showed no statistically significant difference $(p=0.053)$ and a very strong correlation $(0.784)$. The results of the test showed a significant difference $(p=0.001)$ between the overall grading for anterior and posterior teeth.

Conclusion: Students tended to grade their teeth preparations higher compared to the examiner grades, inter examiner variation in the grades existed and the grades of the anterior teeth were higher compared to the posterior teeth.

Keywords: Assessments, Dental students, Evaluations, Grading, Preclinical prosthodontics, Students self assessments.

How to cite this article: Habib SR, Sherfudhin H. Students' Self-assessment: A Learning Tool and Its Comparison with the Faculty Assessments. J Contemp Dent Pract 2015;16(1):48-53.

Source of support: Nil

Conflict of interest: None

\footnotetext{
1,2Department of Prosthodontics, College of Dentistry, King Saud University, Riyadh, Saudi Arabia
}

Corresponding Author: Syed Rashid Habib, Assistant Professor, Department of Prosthodontics, College of Dentistry, King Saud University, Riyadh, Saudi Arabia, Phone: 0096614677441, e-mail: rashi dhabib@hotmail.com

\section{INTRODUCTION}

Assessment in the dental schools represents critical component of successful education in the skills, knowledge, affective processes and professional values that define the competent practice of dentistry. Assessments also discriminate among the candidates for advanced training, provide motivation and direction for learning and judge the adequacy of the training programs. Assessments are used for assessing the cognitive knowledge, psychomotor skills, communication skills and ethical knowledge of the dental students. ${ }^{1-4}$

Dental education is different from other health sciences education. The dental student not only has to understand the biology, physiology and pathology of the oral structures but also develop the skills and judgment needed to restore the nonhealing calcified tooth structure. The development of psychomotor skills like good hand to eye coordination and the ability to visualize the three dimensional objects in fine detail for a dental student are essential components of the dental curriculum. Most of the dental students have no difficulty with the didactic part and its assessment in the dental education because of their past educational experiences. However, the preclinical exercises that prepare them to treat patients clinically are a new experience for the dental students. From preparation of teeth for crowns, fabrication of provisional crowns and the buildup of the teeth with posts and core exercises require development of good hand to eye skills. These psychomotor skills are easier to acquire for those students who have good perception of arts and artistic skills. ${ }^{5-7}$

Decisions regarding which assessment methods to use for various purposes in dental education can be difficult. Identifying and implementing effective methods for assessing dental student performance are ongoing challenges for dental educators. New techniques are emerging replacing the traditional methods of assessments. The optimal assessment plan it to use the right technique for the right reasons, at the right time, and with the right group of students in order to make the right decisions about the right competencies that the student will need to function independently after graduation from the dental school. ${ }^{8-12}$ 
During the practical exercises usually the instructors assesses the dental students' performance. However, the inter instructor variability in the assessments is a concern. Lilley et al and Fuller found significant disagreement between the assessments for different examiners. ${ }^{13,14}$ Investigations in more recent years have concentrated on the development of grading systems based on specific criteria and checklists. This helps in teaching and can provide faculty members with a tool that can be useful in evaluating dental students' performance. This also provides the students with clear expectations of performance, an opportunity to self-assess, and timely detailed feedback. ${ }^{15,16}$

The ability of the dental students to self-evaluate their work can be a very effective learning tool as it enhances the students' performance with each exercise. Understanding the evaluation criteria, being able to visualize the ideal and being able to evaluate against the ideal are skills that needed to be developed. The most distinguishing feature of the health care profession is the ability of its members being able to honestly and competently assess themselves. Accurate self-assessment is the ability to accurately assess one's own strengths and weaknesses and is fundamental to self-directed lifelong learning and to continued competence in the health professions. ${ }^{17-20}$

Generally, the students do not accurately self-assess because they tend to evaluate higher than the instructors evaluations. Despite this observation, most educators agree that self-assessment is potentially valuable. However, there has been a reluctance to embrace the use of this technique. ${ }^{21,22}$ The purpose of the current research was to compare the student's self-grades with the experienced examiner's grades, the inter examiner variation in the grades and to investigate the difference between the grades for the anterior versus posterior teeth. The results obtained will be helpful for enhancing the student's ability to learn and improve the assessment methods in the preclinical prosthodontic courses.

\section{METHODS}

The study was conducted in a preclinical fixed prosthodontic setup at College of Dentistry, King Saud University, Riyadh, Saudi Arabia. Seventy-five students and two examiners participated in the study. A written consent was taken from the students who were willing to participate in the study and their confidentiality was maintained. The students and examiner grades were recorded with self-designed criteria-based evaluation form. An attempt was made to cover all the aspects of tooth preparations with in the form and these criteria were taken from universally accepted text books. ${ }^{23,24}$ This type of grading system has been used in the past by Cho et al. ${ }^{5} \mathrm{~A}$ maximum score of 10 marks can be scored for each student per tooth. The criteria for scoring 10 included the grades for occlusal reduction, axial reduction, taper, margin placement, finish margins and walls, preservation of adjacent tissues and time management. A maximum of 1.5 marks and minimum of 0 mark can be scored in each of the categories.

The students were explained and instructed about the grades distribution before the start of the tooth preparations. The students had been introduced to this self-grading in the previous exercises and were familiar with the process. Students trying to cheat, prepared a wrong tooth or was unable to finish the exam were excluded from the study. The students prepared one anterior (upper central incisor, tooth \# 21) and one posterior (lower first molar, tooth \# 46) ivorine teeth (KaVo Dental, GmbH, D88400 Biberach/RiB) for full veneer metal ceramic crowns in allocated time of 2 hours and 30 minutes. A silicone putty index (Ivoclar, Vivadent Inc.) was made by each student for the teeth before the preparations and was used for evaluating the depth of the tooth preparations. All the dental simulation units (KaVo Dental $\mathrm{GmbH})$, dentoforms (KaVo Dental GmbH) and burs (Mani Inc, Japan) used were standardized for each student.

After the completion of the preparations the dental students had 10 minutes for evaluation of their preparations based on the criteria explained earlier and generated students self-grades. Two faculty members who had more than 10 years of teaching experience in fixed prosthodontics were selected as examiners. The examiners were familiarized with the grading system and calibrated by the course director. However, the examiners were not aware of the students and their identification numbers to help eliminate any bias. The examiners completed the grading for the prepared teeth and generated examiner grades. All the grades were recorded and analysis made using SPSS version. ${ }^{21}$ Analyses included the mean values and standard deviations for the grades by the students, the two examiners and for the two types of teeth. Comparisons were made using Paired sample t-test, independent sample t-test and one way ANOVA post hoc Games-Howell test. The probability for statistical significance was set at $\alpha<0.05$.

\section{RESULTS}

The purpose of this study was to compare the grading of the tooth preparations in a preclinical prosthodontic setup by the faculty with the students self-grading. Other objectives of the study were to investigate the inter examiner variations in the grading of preclinical tooth 
preparations and if there is any difference in the grades for anterior and posterior teeth.

Seventy-five students participated in the study. Each student prepared one central incisor (anterior) and one lower first molar (posterior) and completed their selfassessments. Two examiners, examiner 1 and examiner 2 also completed the assessments. Table 1 describes the means of the grades by the examiners and the students and their comparison. The overall mean of grades by the examiners was $(7.32 \pm 1.39)$ and by the students was $(8.32 \pm$ $0.85)$. The differences between the means of grades by the students were found to be higher for the anterior as well as posterior teeth. However, the difference between the two grades was more for the posterior teeth as compared to the anterior teeth. Comparing the two means of grades for the anterior teeth, posterior teeth and the overall grades showed a statistically significant difference $(p=0.000)$. A moderate correlation (0.399) and a strong correlation (0.601) were found between the grades of the examiners and the students for the anterior and posterior teeth respectively.

For the interexaminer comparison, paired sample t-test was used (Table 2). A statistically significant difference $(\mathrm{p}=0.001)$ and a strong correlation (0.684) was found between the two faculty for the grading of anterior teeth while for the grading of the posterior teeth no significant difference $(\mathrm{p}=0.430)$ and a very strong correlation $(0.844)$ was found. The overall grading for the anterior and posterior teeth by the two faculty members showed no statistically significant difference $(p=0.053)$ and a strong correlation (0.784).

Independents sample t-test was applied for comparing the means of the grades for anterior and posterior teeth by the examiners and the students (Table 3 ). The results of the test showed a significant difference $(\mathrm{p}=0.001)$ between the overall grading for anterior and posterior teeth. The difference between the mean values for the anterior and posterior teeth grading by the student was 0.24 and was found statistically nonsignificant $(p=0.093)$.

Graph 1 describes the difference in the grades by the two examiners and by the students for the anterior and posterior teeth. The overall grades by the students were found to be higher as compared to the grades by the examiners.

Table 4 describes the comparison of the grades for anterior and posterior teeth between the examiner 1, examiner 2 and students by one way ANOVA and post hoc Games-Howell test. A statistically significant difference was found between the grades for the anterior as well as posterior teeth by the students with the grades by the two examiners.

Table 1: Comparison of examiners versus students' grades by paired sample statistics

\begin{tabular}{lllllll}
\hline & Evaluator & ${ }^{*} N$ & Mean & Std. deviation & Pearson's correlation & $p$-value \\
\hline Grades for anterior teeth & Examiners & 150 & 7.58 & 1.11 & 0.399 & 0.000 \\
& Students & 75 & 8.44 & 0.69 & & 0.000 \\
Grades for posterior teeth & Examiners & 150 & 7.06 & 1.59 & 0.601 & 0.000 \\
& Students & 75 & 8.20 & 0.97 & 0.545 & \\
& Examiners & 300 & 7.32 & 1.39 & & \\
& Students & 150 & 8.32 & 0.85 & & \\
\end{tabular}

${ }^{*} \mathrm{~N}$ : Number of assessments

Table 2: Interexaminer comparison of grades for anterior and posterior teeth by paired sample statistics

\begin{tabular}{lllllll}
\hline & Evaluator & ${ }^{*} N$ & Mean & Std. deviation & Pearson's correlation & $p$-value \\
\hline Grades for anterior teeth & Examiner 1 & 75 & 7.3800 & 1.18 & 0.684 & 0.001 \\
& Examiner 2 & 75 & 7.7800 & 1.24 & & 0.844 \\
Grades for posterior teeth & Examiner 1 & 75 & 7.1067 & 1.57 & & 0.430 \\
& Examiner 2 & 75 & 7.0200 & 1.75 & \multirow{2}{*}{0.784} & 0.053 \\
& Examiner 1 & 150 & 7.243 & 1.39 & & \\
& Examiner 2 & 150 & 7.400 & 1.56 & & \\
\hline
\end{tabular}

${ }^{*} \mathrm{~N}$ : Number of assessments

Table 3: Comparison of grades for anterior and posterior teeth by different evaluators

\begin{tabular}{llllll}
\hline Evaluator & Teeth & ${ }^{*} N$ & Mean & Std. deviation & $p$-value \\
\hline Examiners & Anterior & 150 & 7.58 & 1.11 & 0.023 \\
\multirow{3}{*}{ Students } & Posterior & 150 & 7.06 & 1.59 & 0.093 \\
& Anterior & 75 & 8.44 & 0.69 & 0.97 \\
Overall grades & Posterior & 75 & 8.20 & 1.15 & 0.001 \\
& Anterior & 225 & 7.86 & 1.56 & \\
\hline
\end{tabular}

${ }^{*} \mathrm{~N}$ : Number of assessments 


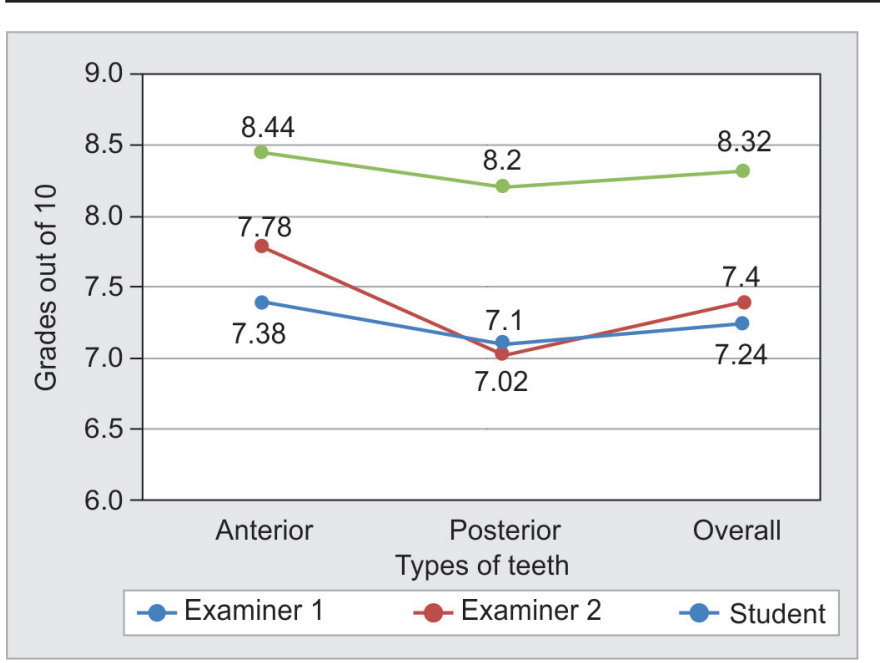

Graph 1: Comparison of grades between the examiners and students

\section{DISCUSSION}

The most distinguishing characteristic of a profession is the self-assessment of the quality of work. This characteristic involves the members of the profession to assess their own work accurately, honestly and competently. The ability to accomplish this self-assessment requires training, practice and helps the professional to know about his/her strengths and weaknesses. ${ }^{5}$ In the health professions like dentistry it is even more important for the professional's self-directed lifelong learning. ${ }^{25}$

The basic technique for the preparation of the teeth for the crowns is important in the dental treatment for various indications and is therefore an essential part of the preclinical prosthodontic teaching. To achieve the competency in this psychomotor domain for the dental students is critical because it requires the three dimensional conceptualization, accuracy, reproducibility and assessments of the different preparation designs. ${ }^{26} \mathrm{Stu}-$ dents tend to perceive that assessment methods are somewhat arbitrary due to lack of examiner consistency. This concept can produce a negative effect on undergraduate confidence and performance level, and undermine the learning process. Much of the literature on assessment in dental schools has focused on strategies to improve calibration among raters in preclinical laboratory courses and the clinic with substantial emphasis on calibration techniques to increase consistency among evaluators and making adjustments for 'hawk' (hard) and 'dove' (easy) raters. ${ }^{4-12}$

Geopferd and Kerber ${ }^{27}$ used analytical rubrics for evaluation using specific criteria and a checklist in an attempt to reduce variability among examiners. They reported that the technique was better than the glance and grade method in reducing variability among examiners. Scott et $\mathrm{al}^{28}$ considered a criteria list to be helpful in achieving more objective results. In the present study, the checklist method based on specific criteria was employed for the evaluation of tooth preparation by the students and the instructors and the overall mean of grades by the examiners was $7.32 \pm 1.39$ and by the students was $8.32 \pm$ $0.85(p=0.00)$. From the results of this study, it appeared that the students were unable to assess their own preparations realistically compared to the examiners whom are considered to be the experts is this domain. The student tended to grade themselves higher compared to the examiners. This finding is consistent with the published literature. Pyle et $\mathrm{al}^{10}$ found that the weaker students were evaluating their own projects higher compared to the faculty evaluations. Gordon, ${ }^{25}$ Edwards et $\mathrm{al}^{29}$ and Arnold et $\mathrm{al}^{30}$ presented similar findings. Kruger and Dunning $^{31}$ in their study found that if people are unskilled in a particular domain, their incompetence robs them of the metacognitive ability to realize it: they will be less able than their more competent peers to recognize competence when they see it and it could be reason for higher grading awarded by the students as compared to

Table 4: Descriptive and analysis of variance results comparing grades of examiners and students for anterior and posterior teeth

\begin{tabular}{|c|c|c|c|c|c|c|c|c|c|c|}
\hline \multirow[t]{2}{*}{ Teeth } & \multirow[t]{2}{*}{ Evaluator } & \multirow[t]{2}{*}{ Mean } & \multirow[t]{2}{*}{$\begin{array}{l}\text { Std. } \\
\text { deviation }\end{array}$} & \multicolumn{2}{|c|}{$\begin{array}{l}95 \% \text { Confidence } \\
\text { interval for mean }\end{array}$} & \multirow[t]{2}{*}{$\begin{array}{l}\text { Anova } \\
\text { p-value }\end{array}$} & \multicolumn{4}{|c|}{$\begin{array}{l}\text { Multiple comparisons by } \\
\text { post hoc games-howell test }\end{array}$} \\
\hline & & & & Lower bound & Upper bound & & & & & \\
\hline \multirow[t]{4}{*}{ Anterior } & E1 & 7.38 & 1.18 & 7.10 & 7.65 & $0.000^{*}$ & E1 & E1 & E2 & $S$ \\
\hline & $(n=75)$ & & & & & & & 0 & 0.113 & 0.000 * \\
\hline & $\begin{array}{l}\text { E2 } \\
(n=75)\end{array}$ & 7.78 & 1.25 & 7.49 & 8.06 & & E2 & 0.113 & 0 & $0.000^{*}$ \\
\hline & $\begin{array}{l}S \\
(n=75)\end{array}$ & 8.44 & 0.69 & 8.28 & 8.59 & & $\mathrm{~S}$ & $0.000^{*}$ & $0.000^{*}$ & 0 \\
\hline \multirow[t]{4}{*}{ Posterior } & E1 & 7.10 & 1.57 & 6.74 & 7.46 & $0.000^{*}$ & E1 & E1 & E2 & $\mathrm{S}$ \\
\hline & $(n=75)$ & & & & & & & & 0.946 & $0.000^{*}$ \\
\hline & $\begin{array}{l}\mathrm{E} 2 \\
(\mathrm{n}=75)\end{array}$ & 7.02 & 1.75 & 6.61 & 7.42 & & $\mathrm{E} 2$ & 0.946 & 0 & $0.000^{*}$ \\
\hline & $\begin{array}{l}S \\
(n=75)\end{array}$ & 8.20 & 0.97 & 7.98 & 8.43 & & $\mathrm{~S}$ & $0.000^{*}$ & $0.000^{*}$ & 0 \\
\hline
\end{tabular}

${ }^{*}$ p-value was significant at less than 0.05; E1: Examiner 1; E2: Examiner 2; S: Students 
the experienced faculty in the current study. The use of the check list method of grading (objective) provide clear rules for evaluation and define criteria for performance. Rubrics speak to both teaching and learning expectations and outcomes and can provide faculty members with a tool that can be useful in evaluating dental student performance. Rubrics can also provide students with clear expectations of performance, an opportunity to self-assess and, timely, detailed feedback. ${ }^{14-16}$

The result of the present study showed inconsistency among examiners (examiner 1 versus examiner 2 ) in grading anterior teeth $(p=0.001)$ whereas in the grading of the posterior teeth no significant difference $(\mathrm{p}=0.430)$ was found (Table 2). The calibration among examiners which is often overlooked, may be the reason for such discrepancy. The overall grading for the anterior and posterior teeth by the two examiners showed no statistically significant difference $(p=0.053)$. Feil ${ }^{32}$ analyzed the reliability of a laboratory evaluation system and demonstrated that reliability can be increased through the use of two raters as opposed to the traditional use of only one. In the present study, two examiners graded the same project and the mean was projected as the final grade which averaged out the discrepancy between the two examiners and this grade was compared with that of the students grading to produce more consistent results. It is not simple to establish evaluation methods for the students' technical performance in the preclinical practice but the objective method employed in the present study could possibly iron out some of the issues related to the subjective method. In recent years, CADCAM technology have been utilized to visualize the difference (s) between tooth preparations and an ideal tooth preparation and to quantify the differences. It can also compare student's preparation to an unprepared tooth with a high degree of accuracy. In a study by Renne et $\mathrm{al}^{33}$ the computer generated results were found to be more precise than the hand-graded method. However, newer technology should be carefully assessed for its accuracy, precision, reliability, effectiveness and feasibility before implementation as most of these technologies are expensive and need customization of the software to suit different courses and could be the reason why the use of such digital dental evaluation systems are not currently in common practice.

Also the results of the study demonstrated variability in the grades for the anterior and posterior teeth by the examiners as well as students. All the evaluators graded the anterior teeth (central incisor) higher compared to the posterior teeth (molar). The comparisons of the overall grades revealed a statistically significant difference $(\mathrm{p}=0.001)$ (Table 3$)$. These differences may be attributed to overall differences in visual and mechanical access, fulcrum of the working hand, preparation under direct vision for the anterior teeth and difficulties in preparing the occlusal surface of the posterior teeth. To the authors knowledge no study is reported comparing the grades of anterior and posterior teeth but Stephen $\mathrm{et}^{\mathrm{a}} \mathrm{l}^{34}$ in a study found a difference between the total occlusal convergence of molars, premolars and incisors preparations by the students. This reveals that the location of the teeth to be prepared may also influence the quality of the preparation. Further research is recommended to see if there is any difference in the grades of teeth according to their location.

\section{CONCLUSION}

Within the limitations of this study, it was found that the students tended to grade their teeth preparations higher compared to the examiner grades in a preclinical fixed prosthodontic setup. Inter examiner variation in the grades existed and can be minimized with the use of criteria based assessments. The quality of the teeth preparation can be affected based on the location of the teeth.

\section{REFERENCES}

1. Albino JE, Young SK, Neumann LM, Kramer GA, Andrieu SC, Henson L, Horn B, Hendricson WD. Assessing dental students' competence: best practice recommendations in the performance assessment literature and investigation of current practices in predoctoral dental education. J Dent Educ 2008 Dec;72(12):1405-1435.

2. Epstein RM, Hundert EM. Defining and assessing professional competence. JAMA. 2002 Jan 9;287(2):226-235.

3. Krupat E, Dienstag JL. Commentary: Assessment is an educational tool. Acad Med 2009 May;84(5):548-550.

4. Norman GR. Defining competence: a methodological review. In: Neufeld VR, Norman GR, eds. Assessing Clinical Competence. New York, NY: Springer; 1985. p. 15-35.

5. Cho GC, Chee WW, Tan DT. Dental students' ability to evaluate themselves in fixed prosthodontics. J Dent Educ 2010 Nov;74(11):1237-1242.

6. Edwards WS, Morse PK, Mitchell RJ. A practical evaluation system for preclinical restorative dentistry. J Dent Educ 1982; 46(12):693-696.

7. Curtis DA, Lind SL, Dellinges M, Setia G, Finzen FC. Dental students' self-assessment of preclinical examinations. J Dent Educ 2008 Mar;72(3):265-277.

8. Tedesco LA. Issues in dental curriculum development and change. J Dent Educ 1995;59(1):97-147.

9. Hendricson WD, Cohen PA. Oral health care in the 21st century: implications for dental and medical education. Acad Med 2001;77(12):1181-1206.

10. Pyle M, Andrieu SC, Chadwich DG, Chmar JE, Cole JR, George MC, et al. The case for change in dental education. J Dent Educ 2006;70(9):921-924.

11. Hendricson WD. Changes in educational methodologies in predoctoral dental education: Finding the perfect intersection. J Dent Educ 2012;76(1):118-141. 
12. Renne WG, McGill ST, Mennito AS, Wolf BJ, Marlow NM, Shaftman S, Holmes JR. E4D compare software: an alternative to faculty grading in dental education. J Dent Educ 2013 Feb;77(2):168-175.

13. Lilley JD, Bruggen Cate HJ, Holloway PJ, Holt JK, Start KB. Reliability of practical tests in operative dentistry. Br Dent J 1968;125(5):194-197.

14. Fuller JL. The effects of training and criterion models on inter-judge reliability. J Dent Educ 1972;36(4):19-22.

15. O’Donnell JA, Oakley M, Haney S, O'Neill PN, Taylor D. Rubrics 101: a primer for rubric development in dental education. J Dent Educ 2011;75(9):1163-1175.

16. Montgomery K. Authentic tasks and rubrics: going beyond traditional assessments in college teaching, College Teaching 2002;50:34-39.

17. Mould MR, Bray KK, Gadbury-Amyot CC. Student selfassessment in dental hygiene education: a cornerstone of critical thinking and problem-solving. J Dent Educ 2011; 75(8):1061-1072.

18. Khatami S, MacEntee MI. Evolution of clinical reasoning in dental education. J Dent Educ. 2011 Mar;75(3):321-328.

19. Forehand LS, Vann WF Jr, Shugars DA. Student self-evaluation in preclinical restorative dentistry. J Dent Educ 1982 Apr;46(4):221-226.

20. Blanch-Hartigan D. Medical students' self-assessment of performance: results from three meta-analyses. Patient Educ Couns 2011 Jul;84(1):3-9.

21. Woolliscroft JO, TenHaken J, Smith J, Calhoun JG. Medical students' clinical self-assessments: comparisons with external measures of performance and the students' selfassessments of overall performance and effort. Acad Med 1993;68(4):285-294.

22. Arnold L, Willoughby TL, Calkins EV. Self-evaluation in undergraduate medical education: a longitudinal perspective. J Med Educ 1985;60(1):21-28.

23. Shillingburg HT Jr, Hobo S, Whitsett LD, et al: Principles of tooth preparations: In Shillingburg HT Jr, Hobo S, Whitsett
LD, et al. Fundamentals of Fixed Prosthodontics 3rd ed. Chicago, Quintessence; 1997. p. 119-154.

24. Rosenstiel S, Land M, Fujimoto J. Contemporary fixed prosthodontics 4th ed. St Louis: Mosby Elsevier; 2006.

25. Gordon MJ. A review of the validity and accuracy of selfassessments in health professions training. Acad Med 1991; 66(12):762-769.

26. Yoon SS, Cheong C, Preisser J Jr, Jun S, Chang BM, Wright RF. Measurement of total occlusal convergence of 3 different tooth preparations in 4 different planes by dental students. J Prosthet Dent 2014 Aug;112(2):285-292.

27. Goepferd SJ, Kerber PE. A comparison of two methods for evaluating primary Class II cavity preparations. J Dent Educ 1980;44(9):537-542.

28. Scott BJ, Evans DJ, Drummond JR, Mossey PA, Stirrups DR. An investigation into the use of a structured clinical operative test for the grading of a clinical skill. Eur J Dent Educ 2001;5:31-37.

29. Edwards RK, Kellner KR, Sistrom CL, Magyari EJ. Medical student self-assessment of performance on an obstetrics and gynecology clerkship. Am J Obstet Gynecol 2003;188(4): 1078-1082.

30. Arnold L, Willoughby TL, Calkins EV. Self-evaluation in undergraduate medical education: a longitudinal perspective. J Med Educ 1985;60(1):21-28.

31. Kruger J, Dunning D. Unskilled and unaware of it: how difficulties in recognizing one's own incompetence lead to inflated self-gradings. J Pers Soc Psychol 1999;77:1121-1134.

32. Feil PH. An analysis of the reliability of a laboratory evaluation system. J Dent Educ 1982;46(8):489-494.

33. Renne WG, McGill ST, Mennito AS, Wolf BJ, Marlow NM, Shaftman S, Holmes JR. E4D compare software: an alternative to faculty grading in dental education. J Dent Educ 2013 Feb; 77(2):168-175.

34. Yoon SS, Cheong C, Preisser J Jr, Jun S, Chang BM, Wright RF. Measurement of total occlusal convergence of 3 different tooth preparations in 4 different planes by dental students. J Prosthet Dent 2014 Aug;112(2):285-292. 